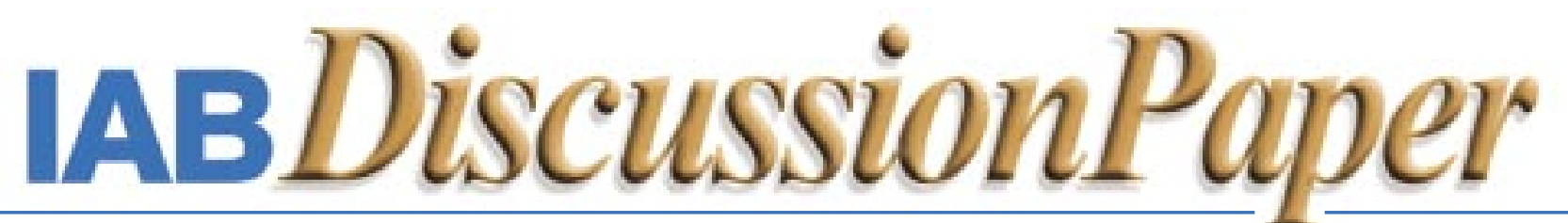

Beiträge zum wissenschaftlichen Dialog aus dem Institut für Arbeitsmarkt- und Berufsforschung

No. $22 / 2005$

\title{
Strike Activity and Centralisation in Wage Setting
}

Johannes Ludsteck, Peter Jacobebbinghaus 


\title{
Strike Activity and Centralisation in Wage Setting
}

Johannes Ludsteck, Peter Jacobebbinghaus (IAB)

Auch mit seiner neuen Reihe „IAB-Discussion Paper“ will das Forschungsinstitut der Bundesagentur für Arbeit den Dialog mit der externen Wissenschaft intensivieren. Durch die rasche Verbreitung von Forschungsergebnissen über das Internet soll noch vor Drucklegung Kritik angeregt und Qualität gesichert werden.

\begin{abstract}
Also with its new series "IAB Discussion Paper" the research institute of the German Federal Employment Agency wants to intensify dialogue with external science. By the rapid spreading of research results via Internet still before printing criticism shall be stimulated and quality shall be ensured.
\end{abstract}




\title{
Strike Activity and Centralisation in Wage Setting
}

\author{
Johannes Ludsteck \& Peter Jacobebbinghaus* \\ Institut für Arbeitsmarkt- und Berufsforschung Nürnberg (IAB) \\ Regensburger Str. 104 \\ 90478 Nürnberg \\ $++49 / 911 / 179-4810,++49 / 911 / 179-1765$ \\ johannes.ludsteck@iab.de, peter.jacobebbinghaus@iab.de
}

January 29, 2006

\begin{abstract}
We test the theoretical claim that coordination and centralisation in wage setting reduce strike activity by estimating nonlinear regression models using a dataset of 17 OECD countries for the period 1972-2000. We find moderating effects of coordination on strike activity but the effects are not stable over time. Several means are employed to check for the robustness of our results. We compute bootstrapped standard errors, conduct nonlinear median regressions. A remaining problem of the study is that we cannot control completely for country-specific heterogeneity in the estimates of coordination and centralisation effects.
\end{abstract}

JEL codes: J51, J52

\footnotetext{
${ }^{*}$ Corresponding author: Johannes Ludsteck. This paper was written as part of the research project "Tarifgebundenheit, Lohnbildung und Ausbildungsanreize" within the DFG priority program "Flexibility in Heterogenous Labor Markets". Financial support from the German Science Foundation (DFG) gratefully acknowledged. We thank Ekkehart Schlicht, François Laisney, Joachim Möller, Christian Dustmann, Lutz Arnold, Harry Haupt, and Kurt Raster for helpful comments and suggestions on earlier versions of the paper, and Hagen Lesch (IW Köln) for providing the strike volume data. Of course, all remaining errors are ours.
} 
Keywords: wage setting, bargaining, strike activity, unions, centralisation in wage setting, corporatism, panel econometrics, robust estimation, LAD, quantile regression, moving-blocks bootstrap, Box-Cox transformation. 


\section{Introduction}

The moderating effects of centralisation in wage bargaining on strike activity are considered as a stylised fact by many economists (Hoel, Moene, \& Wallerstein, 1993, p. 103. Berthold \& Fehn, 1996, p. 82). The theoretical rationale is based on Hicks' (1962) observation that strikes cannot occur in bargaining models based on perfect symmetric information, since rational agents can agree ex ante on the outcome resulting after a strike and thus avoid a harmful/costly strike. If strikes are caused by uncertainty and asymmetric information, centralisation of wage setting should have a moderating effect since wage setting at higher levels is based on aggregate and consequently more 'objective' data (e.g. productivity growth data provided by statistical offices) and these data are (symmetrically) available to all bargaining parties. Modern theoretical models of strikes (see e.g. Kennan \& Wilson, 1989, 1990, 1993) are in line with this reasoning: Strikes serve as screening devices to extract private information (regarding profits, strike funds, willingness to strike of the work force etc.) of the opponent.

The popular information asymmetry argument is complemented with the notion of self serving bias put forward by Babcock \& Loewenstein (1997). They criticise the 'rational agents assumption', by arguing that direct involvement in negotiations biases perceptions (of fairness) in favour of the own position. As a consequence, the sum of claimed shares in the whole cake (the sum in dispute) is typically greater than one. In the light of the (mainly experimental) evidence cited in Babcock \& Lowenstein's article, centralisation may help decreasing strike activity if centralised bargaining is conducted by more specialised and professional negotiators. Babcock \& Lowenstein, however, put a question mark behind this interpretation by stressing that professionals are not necessarily immune against self serving bias.

Though the relation between centralisation in wage setting and strike activity seems to be clear in theory, empirical evidence on the issue is rare. The only exceptions seem to be Cameron (1984) and Schnabel (1993). Cameron finds positive (bivariate) correlations between strike activity (measured as lost days due to strikes per year and workers) and the macroeconomic indicators inflation, unemployment and growth rate of earnings. Schnabel (1993) obtains significant negative rank correlations between strike activity and the centralisation indicators of Calmfors \& Driffill (1988) and Bruno \& Sachs (1985) for a cross section data set of OECD countries. ${ }^{1}$

\footnotetext{
${ }^{1}$ Two further contributions provide rather indirect evidence. Lesch (2002) computes
} 
Though the theoretical literature on bargaining is mainly concerned with centralisation (measured as the dominant level of bargaining) empirical considerations and studies suggest that the degree of coordination (more importantly) between and within the bargaining parties matters as well. A glance at the data shows that national labour markets differ significantly with respect to the degree of coordination, and that the correlation between centralisation and coordination is only moderate. Furthermore the effects of coordination and centralisation in strikes appear to be quite different at the descriptive level. In table 1 we have listed mean and median strike duration by coordination and centralisation. To this aim we have sorted the countries intro three groups according to their scores in the OECD centralisation and coordination indicators. ${ }^{2}$

In the upper panel of table 1 the relation between centralisation and strike volume is u-shaped for the mean as well as for the median, favouring the intermediate level. With respect to coordination the relation is hump-shaped for the mean and monotone decreasing for the median, clearly favouring high degrees of coordination. A further important stylised fact from simple descriptive measures (lower panel of the table) regards the clear negative trend. Since these effects may, however, be generated by spurious correlations (i.e. are not partial effects), we have to apply regression techniques in order to disentangle matters.

\section{Outline of the Empirical Model}

We explain strike-volume (lost working days per 1000 workers and year due to strike actions) by indicators for coordination or the level of centralisation of bargaining and several control variables (explained below). Our choice of coordination and centralisation indicators is OECD04 (2004) (cf. also OECD, 1997). The indicators $C O$ und $C E$ represent the dominant level and degree of coordination of the bargaining parties. Table 5 in the appendix

bivariate correlations between strike incidence and an index of institutional regulations on bargaining (peace clauses, compulsory arbitration, statutory work councils, legal admissibility of lockouts and general strikes) but fails to detect significant effects, and Ochel \& Selwitschka (2003) point to a decreasing trend in strike activity for OECD countries. The interesting paper Goerke \& Madsen (2004) exploits strike volume data from 1903-1999 (with gaps) to test several institutional and political theories. Their main institutional variable (ideological orientation of the government), however, captures only possible influences of the political background.

${ }^{2}$ The indicators are characterised and described in more detail below. 
Table 1: Days lost due to strikes per thousand workers and year.

\begin{tabular}{|c|c|c|c|c|c|c|}
\hline \multicolumn{7}{|c|}{ indicator of centralisation (OECD) } \\
\hline low & 231.2 & 118.0 & 21 & 315 & 1 & 1316 \\
\hline intermed. & 184.4 & 40.0 & 3 & 199 & 0 & 1980 \\
\hline high & 269.1 & 107.5 & 21 & 332.5 & 0 & 2007 \\
\hline \multicolumn{7}{|c|}{ indicator of coordination (OECD) } \\
\hline low & 285.6 & 185.0 & 51 & 403 & 10 & 1293 \\
\hline intermed. & 348. & 160.5 & 54 & 332 & 0 & 1980 \\
\hline high & 147.7 & 24.0 & 3 & 152 & 0 & 2007 \\
\hline period & \multicolumn{6}{|c|}{ strike activity by periods } \\
\hline $1971-1980$ & & 202.5 & 21 & 482 & 0 & 2007 \\
\hline $1981-1990$ & 191. & 84.0 & 7.5 & 266 & 0 & 1353 \\
\hline 1991-2000 & 66.1 & 30.0 & 6 & 72 & 0 & 1317 \\
\hline
\end{tabular}

shows the values of the indicators for the countries in our estimation sample. Further details on the definition and measurement of the indicators are given below. Our data set covers 17 OECD countries for the period 1972-2000.

All specifications contain the following control variables: standardised unemployment rate $(U N)$ inflation rate $(I N F L)$, output gap $(G A P)^{3}$, union density rate $(D E N)$ together with an interaction term for Ghent systems ${ }^{4}$ $(D E N G=D E N \times I$ (Ghent system)), an openness indicator $(O P E N$, computed as sum of exports divided by GNP), and lagged wage growth rates $(W G R)$. To allow for further variability, the coordinatin and centralisation indicators are interacted with dummies for the decades 1972-1980, 1981-1990 and 1991-2000. This enables us to test explicitly whether the influence of the centralisation indicators is stable over time.

\footnotetext{
${ }^{3}$ Unfortunately, the output gap series provided by the OECD and the IMF are not available for all countries and the whole period of our sample. Therefore we compute an output gap as the relative difference between actual real output (GDP) and its smooth trend (generated by the Hodrick-Prescott Filter, with smoothing parameter value 50 for all countries).

${ }^{4}$ unemployment insurance is in some countries organized by unions implying that union membership is necessary to obtain insurance. Since a part of workers then joins unions mainly to be insured, union density is a bad indicator for union bargaining power in these countries. The interaction term is included to control for this heterogeneity.
} 


\section{Data Problems and Specification Issues}

\subsection{Data Problems}

We anticipate that our estimations suffer from several problems which are common to empirical studies of centralisation effects. ${ }^{5}$ The first and most crucial one stems from the fact that our centralisation and coordination measures have (at most) ordinal scale level, show only little variation in the time dimension and changes are often not clear-cut. Therefore it is impossible to identify coordination effects in a standard fixed effects regression design. We use two alternatives instead. In the first we include only three dummies (interacted with dummies for the three decades) for low, medium and high centr./coord., in the second we include dummies for all countries (interacted with dummies for the three decades) and identify centralisation effects as differences between the respective group (low, medium and high) means of dummy coefficients. Consequently our centralisation effects are a mixture of difference and level effects.

Since we cannot eliminate country-specific heterogeneity completely, neglect of possibly relevant regressors remains an important problem. We do not include some variables representing the institutional and legal framework of bargaining since comparable and reliable data are not available for the whole sample. These are dummies for statutory work councils, compulsory strike ballots, allowance of lock-outs and political strikes, peace clauses, and compulsory arbitration. ${ }^{6}$

We think, however that the neglect of these variables does not generate serious bias in our estimates since most of these variables are directly related to our measures for centralisation and coordination of bargaining, and it is likely that many of these regulations are mainly responses of the political system to the prevailing bargaining institutions. For example, the viability of political strikes depends at least indirectly on the coordination of unions, since

\footnotetext{
${ }^{5}$ We mention only some important studies from the literature: Bruno \& Sachs (1985) Calmfors \& Driffill (1988), Layard, Nickell, \& Jackman (1991), OECD (1997), Iversen (1998, 1999), Elmeskov, Martin, \& Scarpetta (1998) and Haffner, Nickell, Nicoletti, Scarpetta, \& Zoega (2001). For (almost complete) surveys on the issue see Flanagan (1999), Aidt \& Tzannatos (2002) and Booth et al. (2001).

${ }^{6}$ We checked the relevance of these dummy control variables by including them into explorative estimations for the subsample of European countries and found (surprisingly) neither individually significant effects nor joint significance (F-test for all these dummies). These checks do not allow us to give the clear-all, however, since the sample for these estimations relates to a relatively homogenous subsample of the data.
} 
highly decentralised unions lack the structure to organise political strikes. ${ }^{7}$ Therefore political strikes (which generate extreme strike volumes in some years) should be considered as a by-product of coordination, and it would be 'unfair' to net them out by using dummies for political strikes. If we do not control for these variables we have, however, interpret the centralisation and coordination dummy coefficients very carefully. They have to be considered as measures for the bargaining system in a more comprehensive sense, i.e. including the legal and political environment.

Further disclaimers regard our measures of centralisation and coordination in bargaining. They are complex phenomenons and therefore resist persistently to researchers' operationalisation and measurement attempts. As regards centralisation, bargaining can take place at several levels: the national, regional, sector, industry, firm, plant or occupation level. From a theoretical point of view it is impossible to give a unique ordering of this list (just try to rank the regional and industry level with respect to centralisation). Additionally, measurement is complicated significantly if bargaining is conducted at different levels simultaneously (in Germany we observe a combination of industry and regional bargaining). If these problems were resolved, we would have (at least in Germany) to inspect several thousand collective wage agreements because they may differ significantly in scope (e.g. density of workplace an remuneration regulations).

The measurement of coordination appears even more challenging because coordination is often realised tacitly or customarily, i.e. without formal binding contracts, and tacit coordination detracts itself from observation. Even if the observability problem were absent, many dimensions of coordination had to be accounted for: The degree of coordination on the employer and union side may differ and coordination may be realised in different forms: vertical (creation of umbrella organisations) or horizontal integration (associations). Furthermore similar forms of coordination and organisation do not necessarily imply a similar distribution or concentration of power. While umbrella organisations in the highly centralised countries possess sweeping powers, i.e. are able to sign binding contracts on behalf of their member organisations and have control over strike funds, their functions in decentralised countries are typically reduced to services for and exchange of information between the member organisations. Finally, the union and employer side may show different degrees of concentration.

\footnotetext{
${ }^{7}$ Teulings \& Hartog (1998) advance the hypothesis that centralisation and the legal framework both are essentially observable 'incarnations' of underlying social preferences. And they provide 'soft' evidence in favour of their hypothesis.
} 
These short remarks suggest that it is difficult to obtain objective and reliable measures of centralisation. Starting with Blyth (1979), Schmitter (1981), Crouch (1983), Cameron (1984), Bruno \& Sachs (1985), and Tarantelli (1986) empirical work on centralisation has produced a large number of indicators. Calmfors \& Driffill (1988), OECD (1997), Kenworthy (2001) and Aidt \& Tzannatos (2002) provide comparisons. Kenworthy (2001) combines a comparison of indicatores with a sensitivity analysis of their effects in regression models for the unemployment rate and finds that the results of empirical models respond sensitively to the choice of indicators in some cases. We choose the OECD indicators from the large pool of indicators since they are used by many other studies (on the relation between centralisation and wages/unemploymeent/employment) and capture at least important discrete changes of centralisation in the last thirty years. Most other indicators which are not updated since their creation would urge us to put hands-on and introduce additional subjectivity. Though theory does not provide much guidance on further relevant regressors, coverage (share of workers covered by collective wage agreements) suggests itself as a control variable. We did not include coverage rates into the model, since they appear to be less relevant than density rates from a theoretical point of view. Besides that they are highly correlated with union density, but measured less precisely. Therefore we expect that including them will add little information to our model but generate significant collinearity problems.

A glance at a plot of the strike data reveals their main characteristics and the implied problems. Figure 1 visualises the high volatility of our dependent variable and considerable differences between countries. ${ }^{8}$ These sudden changes and significant variations are contrasted by a relatively smooth development of our regressors. Two explanations suggest themselves to fill this gap. The first and most unpleasant one appeals to effects caused by unobserved or unobservable variables. The second one appeals to nonlinearity.

Bias caused by unobserved variables cannot be eliminated. If they are responsible for the extreme observations of the dependent variable, this bias can be reduced somewhat by application of robust estimators. Our choice is the least absolute deviations (LAD) estimator. The LAD estimator $\beta$ minimises the sum of absolute deviations $\left|y_{i t}-\beta x_{i t}\right|$ putting smaller weight than OLS estimates on points located far away from the regression line.

\footnotetext{
${ }^{8} \mathrm{~A}$ disclaimer regarding the comparability if strike data is in order here. Lesch (2002) and Schnabel (1995) point to the fact that strike data are censored from below at the firm level in the USA because only strikes with more than 1000 days lost are reported. According to Lesch and Schnabel this may lead to an underestimation of the true strike activity by $30 \%$.
} 
Figure 1: Lost days due to strikes per 1000 employees and year, 17 OECDcountries
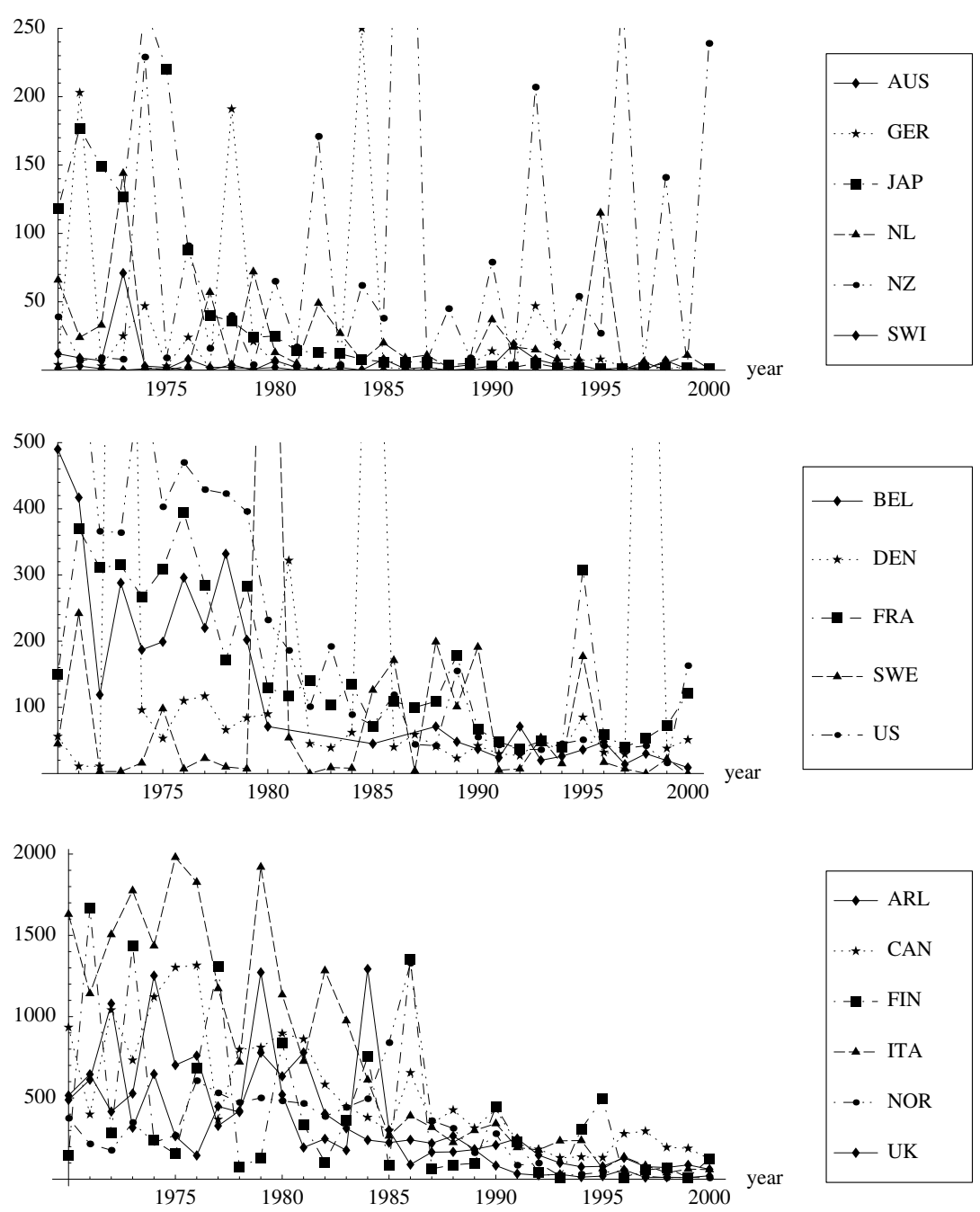

Interestingly, the second candidate for the high volatility of strike volume in face of smooth regressors, nonlinearity, is supported loosely by theoretical reasoning. While screening models predict moderate strike durations (see e.g. Kennan \& Wilson, 1989, 1990, 1993 for surveys), the sum in dispute is likely to be 'burned down' completely in attrition games, implying longlasting strikes. This substantial difference in the outcome is caused by an inconspicious change of the rules: In screening games proposals are possible only within fixed time intervals, while the length of a bargaining round is 
chosen by the agents in signaling and attrition games. An alternative explanation for high volatility appears if we abandon the assumption of rationality. Everyday life is full of casual evidence for the self-energising structure of escalation. If emotions play a significant role, mistaken demands or offers may be misinterpreted by the opponent as provocative action and answered by excessive responses. Consequently small changes in the environment may lead to large spikes in the strike volume.

Before we discuss our suggested economotric solutions to tackle the major data problems we have to mention a minor censoring problem in the data. The reported strike duration is zero for 31 out of 461 observations. ${ }^{9}$ In principle, the censoring problem could be solved by application of appropriate estimation procedures (ML-Tobit, Symmetrically Censored Least Squares (SCLS), Censored Least Absolute Deviations (CLAD), Heckman-Selection). We abstain from using such procedures for two reasons. Firstly, two of these estimators (ML-Tobit and Heckman-Selection) are based on strong (and unrealistic) assumptions regarding the structure of error terms and respond quite sensitively to violations. Secondly, our Box-Cox estimates shown below suggest significant deviations from a linear model which cannot be represented in standard tobit-type models. ${ }^{10}$ Since the censoring problem is negligible in our application (less than $7 \%$ of all observations are censored) but the functional form issue appears to be crucial, we decided to drop the zero-censored observations.

\section{$3.2 \quad$ Specification Issues}

The Box-Cox transformation suggests itself as a tool to tackle the nonlinearity problem in our application. It creates considerable flexibility but imposes less computational burden and mild identification requirements. The speci-

\footnotetext{
${ }^{9}$ Contracting without strikes is distributed very unevenly over the countries: 14 zero observations come from Switzerland, 12 from Austria, three from Sweden, and one from the Netherlands and Germany.

${ }^{10}$ Note however, that a Box-Cox transformed variable cannot be zero. Consequently the Box-Cox transformation is - strictly speaking - senseless for samples containing zero values of the dependent variable. Only Heckman's selection model makes it possible to combine the transformation of the dependent variable with a consistent modelling of zero observations. As is well known from the empirical literature, however, it rests on strong assumptions regarding the error terms and suffers from severe identification problems in most applications.
} 
fication proposed by Box \& Cox (1964) has the form

$$
\frac{y^{\lambda}-1}{\lambda}=X \beta+u \text {. }
$$

Depending on the scaling parameter $\lambda$ it allows a continuous transition from the linear case $(\lambda=1)$ to a logarithmic transformation $(\lambda \rightarrow 0)$ of the dependent variable. We estimate the model (after appropriate transformation with a Jacoby-factor, see Carroll \& Ruppert, 1988 or Powell, 1996) by nonlinear least squares (NLS). ${ }^{11}$ The corresponding nonlinear LAD estimates are computed in a computationally efficient two-step method proposed by Chamberlain (1994), Buchinsky (1995) and Fitzenberger, Wilke, \& Zhang (2004). Exploiting the equivariance property of quantiles with respect to a positive monotone transformation, $\beta_{\lambda}$ can be estimated from model (1) which is linear for given $\lambda$. The optimal $\lambda$ is obtained from minimisation of the $L_{1}-$ Norm of the inverted Box-Cox formula

$$
\mid y-\left(1+\lambda X \beta_{\lambda}\right)^{1 / \lambda}
$$

which amounts to a nonlinear but univariate (and therefore straightforward) minimisation problem. ${ }^{12}$ Fitzenberger et al. (2004) point to the problem that the second step is viable only if the expression in brackets $1+\lambda X \beta$ is strictly positive for all observations. To assure this, they propose to use only observations for which this condition is met in all optimisation steps for both boundaries of an interval $[\underline{\lambda}, \bar{\lambda}]$ which has to be fixed in advance. We choose $\underline{\lambda}=0.0$ and $\bar{\lambda}=1.5 .^{13}$

A third problem present in almost all cross country studies concerns dependencies between residuals. The residuals show considerable serial as well as between-panel correlation. ${ }^{14}$ As is well known, the standard OLS covariance matrix formula $\sigma^{2}\left(X^{\prime} X\right)^{-1}$ produces biased results then. If panel data

\footnotetext{
${ }^{11}$ Below we point to problems associated with GLS or GMM estimation in small samples. Because of this we do not apply Powell's rescaled GMM estimator.

${ }^{12}$ Simultaneous estimation of $\lambda$ and $\beta$ from (1) is not possible since the nonsense solution $\lambda=-\infty, \beta=(0, \ldots, 0)$ minimises the objective function. For further details see the cited literature.

${ }^{13}$ The lower bound $\lambda$ is a compromise in our application because values of $\lambda<0$ generate an excessive loss of observations due to the selection rule. On the other hand the estimated $\lambda$ falls short of the lower bound zero in about 1 percent of the bootstrap iterations. At least for these resamples, $\underline{\lambda}$ has to be decreased. Since we compute (nonparametric) 90 percent confidence intervals, the lower confidence bound (the $5 \%$ percentile) is not affected by these cases, and can therefore be ignored.

${ }^{14}$ Serial correlation for the linear regressions computed below is about 0.5 , and about $20 \%$ of the entries in the between panel correlation matrix of residuals are above 0.5.
} 
are available (as in our case), correct estimation of the covariance matrix is straightforward (see Greene, 2000, section 13.9). Though the estimated covariance matrix of the residuals could in principle be used to compute an efficient GLS estimate, we do not follow this approach here because of the warnings in Beck \& Katz (1995). The authors show in a simulation study that GLS estimates respond sensibly to biased estimation of the residual covariance matrix and GLS standard errors typically are biased downwards. This may cause severe problems, especially if the cross section dimension of the sample is small. At least for linear models application of the sandwich formula $V(\hat{\beta})=\left(\mathbf{X}^{\prime} \mathbf{X}\right)^{-\mathbf{1}}\left(\mathbf{X}^{\prime} \hat{\mathbf{\Omega}} \mathbf{X}\right)\left(\mathbf{X}^{\prime} \mathbf{X}\right)^{-\mathbf{1}}$ is straightforward (and for linear models readily implemented in Stata). Here we apply a (design-matrix) moving-blocks bootstrap ${ }^{15}$ instead for two reasons. Firstly, for the nonlinear LAD models a similar approach would require parametric or nonparametric conditional density estimation of the residuals. While the parametric approach runs counter to the spirit of the robust semiparametric LAD procedure, the nonparametric approach suffers from the well known curse of dimensionality. Secondly, and more importantly, the bootstrap appears to produce more reliable results for small samples and samples with outlying observations. To retain the serial and panel correlation structure of the residuals we draw two-dimensional blocks of length four in the time direction and length six in the cross section dimension. A formal description of the procedure is given in the appendix.

\section{Estimation results}

Our estimations are based on yearly observations for the period 1972-2000 for the OECD countries Austria, Australia, Belgium, Denmark, Germany, Finland, France, United Kingdom, Italy, Japan, Canada, New Zealand, the Netherlands, Norway, Sweden, Switzerland, and the USA. ${ }^{16}$

As theory does us not tell which of the two indicators (centralisation or coordination) is more important for strike activity, the standard econometric

\footnotetext{
${ }^{15}$ David \& Hinkley (1997) and Vinod (1993) provide surveys on the issue, Fitzenberger (1997) contains a thorough analysis of the moving blocks bootstrap for least squares and quantile regression models.

${ }^{16}$ There are three gaps in the strike data for. Belgium (1981-1984, 1986-1987, 1999. Furthermore our wage growth data (source: OECD) start in 1977, 1977 and 1978 for Australia, Norway and Switzerland. We checked the effect of this data loss by dropping the (insignificant) wage variable from the set of regressors and found only small effects on other regressors.
} 
strategy to answer the question were to include both indicators in a regression and let standard errors or p-values decide. Unfortunately this is not viable since the indicators are highly correlated (see table 5 in the appendix). Therefore we follow the custom to estimate separate models for both indicators.

As should be clear from the above remarks regarding the operationalisation and measurement of coordination (and centralisation), the available indicators can be measured sensibly at most by an ordinal scale. The OECD uses a discrete ordinal scale ranging from 1 to 5 . To obtain valid regressor variables, we recoded the indicators into three dummies: low coordination corresponds to value 1 , intermediate coordination to $2-3$, and high coordination to $4-5$. As explained above we interacted the coordination dummies with dummies for the decades to allow for (restricted) time-variability of the considered effects. The recoding of the indicators to dummy variables introduces a subjective component since the researcher has to determine the grouping. The definition of groups is, however, restricted by the distribution of positions in the original measure. As can be seen from the table in the appendix, a grouping scheme of the form 1-2, 3, 4-5 would leave the medium category of the coordination indicator empty for some decades.

To start with, consider the results of the Box-Cox regressions for coordination in table (2). The table is nonstandard in two respects. Firstly, it contains p-values instead of $t$ statistics or standard deviations of coefficients. ${ }^{17}$ The reason for this choice is that p-values based on the quantiles of the distribution of bootstrap coefficients are more robust than the other inference measures. Secondly, since the coefficients of the transformed modell have no direct intuitive interpretation we report average group and average marginal effects of the regressors on the dependent variable are given instead of the coefficients themselves.

The average group effect for the $k$-th dummy regressor $d_{k}$ is

$$
A V G E\left(d_{k}\right)=\frac{1}{C T} \sum_{i, t}\left[\hat{y}_{i, t}\right]_{d_{k}=1}-\left[\hat{y}_{i, t}\right]_{d_{k}=0}
$$

where $C, T$ are the number of countries and years, respectively, and $\left[\hat{y}_{i, t}\right]_{d_{k}=j}$ denotes the prediction from the (inverted) Box-Cox model $y_{i, t}=\left\{1+\lambda\left(x_{i, t} \beta+\right.\right.$

\footnotetext{
${ }^{17}$ The bootstrap $p$-values are computed as solutions to $Q_{p}\left(b_{k}\right)=0$ where $Q_{p}\left(b_{k}\right)$ is the $p$-quantile of the empirical distribution of the $k$-th coefficient $b_{k}$. Since it is (with 1000 bootstrap resamples) unlikely to find a bootstrap realisiation of $b_{k}$ which is exactly zero, we search for the root of an interpolation function $\hat{Q}_{p}\left(b_{k}\right)$ instead.
} 
$\left.\left.\hat{\epsilon}_{i, t}\right)\right\}^{1 / \lambda}$ with the $k$-th dummy set to $j$ (and all other variables take on their empirical values). The average marginal effect $A V M E$ of the $k$-th continuous regressor $x^{k}$ is

$$
A V M E\left(\frac{\partial y}{\partial x_{k}}\right)=\frac{1}{C T} \sum_{i, t}\left[\frac{\partial y}{\partial x^{k}}\right]_{i, k}=\frac{b_{k}}{C T} \sum_{i, t}\left\{1+\lambda\left(x_{i, t} b+\hat{\epsilon}_{i, t}\right)\right\}^{1 / \lambda-1}
$$

Note that the residuals do not cancel out here.

Because of their paramount relevance for specification issues, the estimates of the transformation parameter $\lambda$ are reported in table 4 in the appendix. The estimates of $\lambda$ vary between 0.07 to 0.19 (depending on specification). Note that the upper bounds of $95 \%$ confidence intervals are far away from unity, giving clear evidence against the linear specification. While the estimated values of $\lambda$ differ somewhat with respect to the estimation procedure, the choice of the institutional proxy (in the group-specific effects specification) seems to be irrelevant. Furthermore the NLS procedure delivers more precise results than NLAD.

As already mentioned in the text above, we estimate models with groupspecific and country-specific fixed effects. Each of these models is estimated with transformed NLS and NLAD. Table 2 shows the results for the groupspecific, 3 the results for the country-specific fixed effects model. Since the differences between the tranformed NLS and NLAD model are small to moderate in most cases, we interpret only the NLS results.

Regarding the continuous 'control' variables we find that size and significance of coefficients differs considerably between the group- and country-specific fe models. They are, however, not generally smaller in the country-specific effects model. The most important differences exist for the unemployment rate and the inflation rate. Since the country-fe specification is less restrictive this suggests that the high impacts of these variables seem to be caused by misspecification, i.e. they capture a good deal of country-specific heterogeneity. The output gap, union density and openness indicator remain significant even in the country-fe specification with expected sign. Surprisingly, lagged wage growth is highly insigificant (and even positive). This contradicts microeconometric evidence (see e.g. Card (1990)) from the USA and Canada. Possible explanations are, a) that our business cycle proxy $(G A P)$ does not capture all relevant cycle effects, and b) that - especially in the more centralised countries - several important industrial conflicts (followed by dramatic strikes) are not triggered by wage demands but (e.g. in Germany) related to working time and vacation regulations or are (at least 
Table 2: Mean marginal Effects for the Box-Cox transformation model, group-specific fixed effects specification. Dependent variable: strike volume.

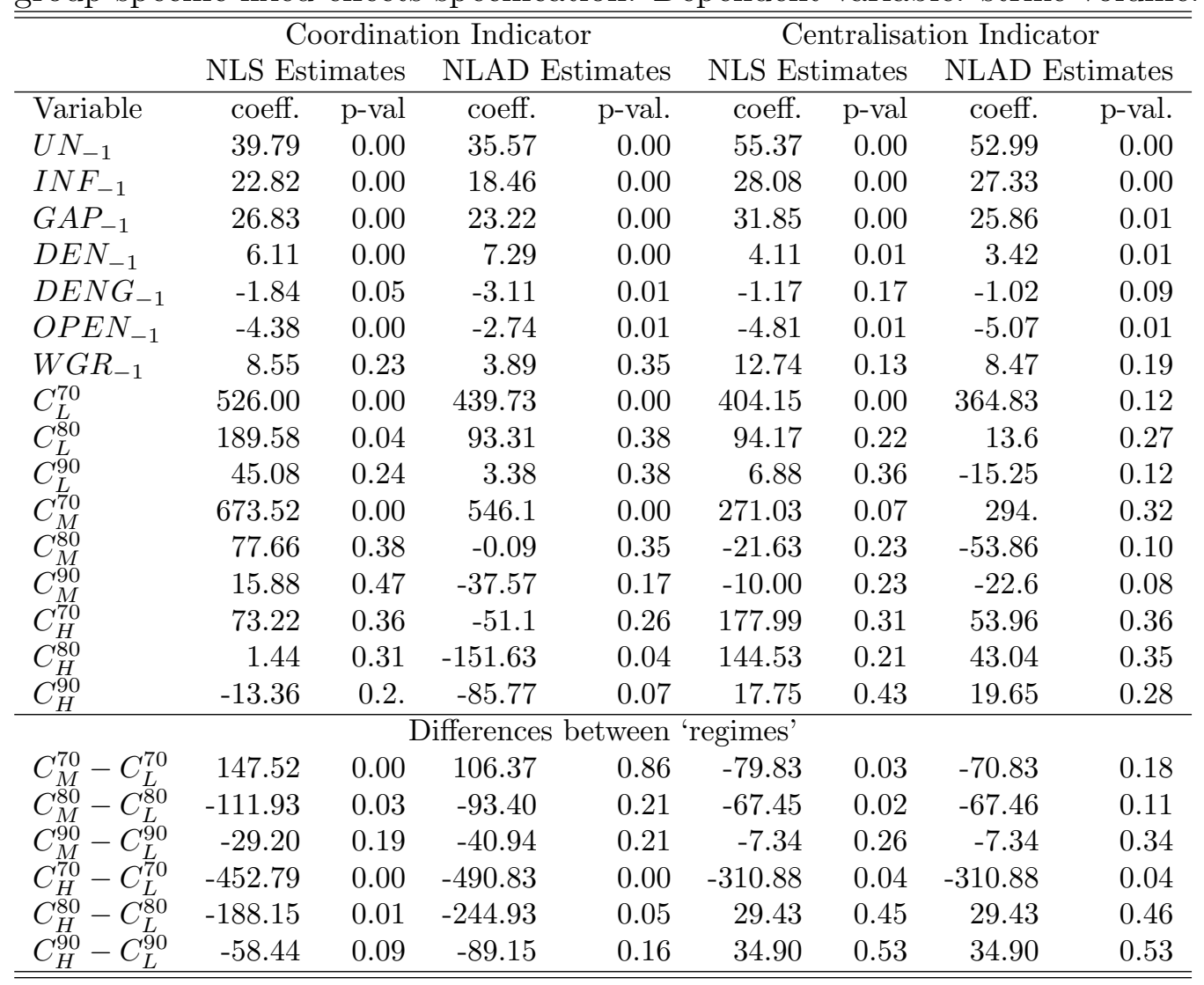

Number of observations: 430

$C_{L}^{d}, C_{M}^{d}, C_{H}^{d}$ : dummy for medium and high degree of coord./cent. in decade $d$ decades: $70: 1972-1980,80: 1981-1990,90: 1991-2000$

$U N_{-1}$ : lagged unemployment rate, $I N F L_{-1}$ : lagged inflation rate

$G A P_{-1}$ : lagged output gap, $D E N_{-1}$ : lagged union density

$D E N G:=D E N \times$ dummy for Ghent system

$O P E N_{-1}$ : lagged trade openness indicator, $W G R_{-1}$ : lagged wage growth

indirectly) directed against governments restricting union power by creating or tightening bargaining regulations. ${ }^{18}$

Note that the impact of the significant variables is (at least in the more trustable country-fe model) only moderate. The output gap is measured in percent, implying that a one percent increase of the difference between actual

\footnotetext{
${ }^{18}$ Important examples are anti-union policies of Reagan in the USA and Thatcher in UK.
} 
and potential GDP increases strike volume by about 15 (days per year and thousan workers). With an average range of about 5 percent for the output gap cyclical variation of strikes amounts to about 75 days.

Finally note that the continuous regressors cannot explain the decrease of strike volume in the considered period. The output gap shows no trend by construction. Union density and opennes both show large between-country differences. ${ }^{19}$ But time-variation is rather small. Average union density decreased from about 45 percent in the seventies to about 40 percent in the nineties, opennes increases from 21 to 33 percent. This implies that increasing opennes is responsible for a 120 day decrease of strike volume in the considered period.

Regarding the central regressors of our investigation we find significant negative effects for high coordination (compared to low coordination), i.e. high coordination decreases the strike volume. However, the most important thing to note here seems to be that the size of the effect decreases considerably from about -450 (group-fe model) or about-200 (country-fe model) in the seventies to about -50 in the nineties.

Evidence is less clear for the centralisation indicator. Here the medium levels seem to have an advantage but significant effects exist only in the country-fe model in the seventies and eighties.

\section{Conclusion}

Though the coefficients for the centralisation and coordination indicators are estimated rather imprecisely and disclaimers regarding the validity and reliability of the used institutional indicators are in order, our investigation shows that high levels of coordination had significant moderating effects on strike activity in the considered period. However, the impact of coordination on strike activity shows a clear decreasing trend, i.e. the less coordinated countries have catched up in the three decades.

For the continuous macro variables which acted mainly as controls in our study we find only small impacts on strike volume, suggesting that the insti-

\footnotetext{
${ }^{19}$ Average density is about 75 and 80 percent for the most organised labour markets in Denmark and Sweden but under 20 percent in the least organised in the USA and France. The openness indicator ranges from unter 10 percent in the USA to more than 60 percent in Belgium.
} 
Table 3: Mean marginal Effects for the Box-Cox transformation model, country-specific fixed effects specification. Dependent variable: strike volume.

\begin{tabular}{lrrrr}
\hline \hline & \multicolumn{2}{c}{ NLS Estimates } & NLAD Estimates \\
\hline Variable & coeff. & p-val & coeff. & p-val \\
$U N_{-1}$ & 6.86 & 0.19 & -3.36 & 0.48 \\
$I N F_{-1}$ & -1.31 & 0.48 & 1.66 & 0.16 \\
$G A P_{-1}$ & 14.38 & 0.01 & 8.60 & 0.03 \\
$D E N_{-1}$ & 12.91 & 0.00 & 8.26 & 0.01 \\
$D E N G_{-1}$ & -19.57 & 0.22 & -6.41 & 0.41 \\
$O P E N_{-1}$ & -10.75 & 0.01 & -7.42 & 0.02 \\
$W G R_{-1}$ & 0.52 & 0.49 & 1.94 & 0.47 \\
\hline Differences between 'regimes', Coordination \\
$C O_{M}^{70}-C O_{L}^{70}$ & 479.88 & 0.07 & 481.46 & 0.06 \\
$C O_{M}^{80}-C O_{L}^{80}$ & -0.921 & 0.47 & 7.73 & 0.43 \\
$C O_{M}^{90}-C O_{L}^{90}$ & -10.04 & 0.18 & -10.46 & 0.24 \\
$C O_{H}^{70}-C O_{L}^{70}$ & -207.30 & 0.05 & -215.0 & 0.04 \\
$C O_{H}^{80}-C O_{L}^{80}$ & -154.60 & 0.00 & -153.84 & 0.02 \\
$C O_{H}^{90}-C O_{L}^{90}$ & -49.99 & 0.00 & -44.70 & 0.02 \\
\hline Differences between 'regimes', Centralisation \\
$C E_{M}^{70}-C E_{L}^{70}$ & -61.91 & 0.05 & -61.53 & 0.09 \\
$C E_{M}^{80}-C E_{L}^{80}$ & -103.66 & 0.00 & -103.60 & 0.01 \\
$C E_{M}^{90}-C E_{L}^{90}$ & -0.53 & 0.24 & 5.11 & 0.38 \\
$C E_{H}^{70}-C E_{L}^{70}$ & -161.23 & 0.13 & -171.28 & 0.13 \\
$C E_{H}^{80}-C E_{L}^{80}$ & $23 .-78$ & 0.38 & 19.80 & 0.49 \\
$C E_{H}^{90}-C E_{L}^{90}$ & 51.65 & 0.34 & 71.61 & 0.46 \\
\hline \hline
\end{tabular}

Number of observations: 430

$C O_{H}^{d}-C O_{L}^{d}$ : difference of group effect between high and low coordination in decade $d$. The group effect $C O_{x}^{d}$ is computed by averaging over all dummy effects of countries belonging to group $x$.

We do not report the group averages of the country-specific fixed effects since they are similar to the group specific intercepts $C O_{i}^{d}$ in table 2 .

decades: $70: 1972-1980,80: 1981-1990,90: 1991-2000$

$U N_{-1}$ : lagged unemployment rate, $I N F L_{-1}$ : lagged inflation rate

$G A P_{-1}$ : lagged output gap, $D E N_{-1}$ : lagged union density

$D E N G_{-1}:=D E N_{-1} \times$ dummy for Ghent system

$O P E N_{-1}$ : lagged trade openness indicator, $W G R_{-1}$ : lagged wage growth

tutional frame (including traditions) plays a paramount role for the explanation of differences in both the cross-section and time dimension.

What to conclude from our results? Though we find statisticall significant effecst of coordination in some periods and variants of the model, they are not stable enough (over time) to create a clear case in favour of better coordination. Even if our evidence were more conclusive, the observation that 
cross-country heterogeneity plays an important role, should deter us from demanding reforms in the less coordinated countries: Firstly, strike activity is only one of many other labour market indicators and welfare losses due to strikes are not large (at least in the last years). And secondly, bargaining institutions depend on and interact with many other institutional, social and economic conditions. Turning only one screw of the complex institutional frame probably would deflagrate without any effects or even worse outcomes. 


\section{References}

Aidt, Toke, \& Tzannatos, Zafiris (2002). Unions and Collective BargainingEconomic Effects in a Global Environment. Washington, D.C.: World Bank.

Babcock, Linda, \& Loewenstein, George (1997). Explaining Bargaining Impasse: The Role of Self-Serving Biases. Journal of Economic Perspectives, 11(1), 109-126.

Beck, Nathaniel, \& Katz, Jonathan (1995). What to Do (and not to Do) With Time-Series Cross-Section Data. American Political Science Review, 89(3).

Berthold, Norbert, \& Fehn, Rainer (1996). Evolution von Lohnverhandlungssystemen - Macht oder ökonomisches Gesetz? In Zolnhöfer Werner (Ed.), Die Tarifautonomie auf dem Prüfstand (Vol. 244, pp. 57-94). Berlin: Duncker und Humboldt.

Blyth, C. (1979). The Interaction between Collective Bargaining and Government Policies in Selected Member Countries. Paris.

Booth, Alison, Clamfors, Lars, Burda, Michael, Checchi, Daniele, Naylor, Robin, \& Visser, Jelle (2001). The Future of Collective Bargaining in Europe. In Boeri Tito, Brugiavini Agar, \& Calmfors Lars (Eds.), The Role of Unions in the Twenty-First Century (pp. 11-45). Oxford: Oxford University Press.

Box, G, \& Cox, D (1964). The Analysis of Transformations. Journal of the Royal Statistical Society, Series B, 26, 211-252.

Bruno, Michael, \& Sachs, Jeffrey (1985). Economics of Worldwide Stagflation. Oxford: Oxford University Press.

Buchinsky, Moshe (1995). Quantile Regression, Box-Cox Transformation Model, and the U.S. Wage Structure 1963-1987. Journal of Econometrics, 65, 109-154.

Calmfors, Lars, \& Driffill, John (1988). Bargaining Structure, Corporatism and Macroeconomic Performance. Economic Policy, 6, 14-61.

Cameron, David (1984). Social Democracy, Corporatism, Labour Quiescence, and the Representation of Economic Interest in Advanced Capitalisit Society. In Order and Conflict in Contemporary Capitalism (pp. 143-178). Oxford: Clarendon Press. 
Card, David (1990). Strikes and Wages: A Test of an Asymmetric Information Model. Quarterly Journal of Economics, 625-659.

Carroll, R, \& Ruppert, D (1988). Transformation and Weighting in Regression. London: Chapman and Hall.

Chamberlain, Gary (1994). Advances in Econometrics: Sixth World Congress [Monograph]. In (Vol. 1). Econometric Society: Christopher Sims.

Crouch, Colin (1983). The Politics and Sociology of World Inflation. In Lindberg L \& Maier C (Eds.), (pp. 134-153). Washington: Brookings Institution.

David, A. C., \& Hinkley, D. V. (1997). Bootstrap Methods and their Applications (first ed.). Cambridge: Cambridge University Press.

Elmeskov, Jorgen, Martin, John, \& Scarpetta, Stefano (1998). Key Lessons for Labour Market Reforms: Evidence from OECD Countries' Experiences. Swedish Economic Policy Review, 5(2).

Employment outlook. (2004). Paris.

Fitzenberger, Bernd (1997). The Moving Blocks Bootstrap and Robust Inference for Linear Least Squares and Quantile Regression. Journal of Econometrics, 235-287.

Fitzenberger, Bernd, Wilke, Ralf, \& Zhang, Xuan (2004). A Note on Implementing Box-Cox Quantile Regression (Mimeo). Frankfurt and Mannheim: University of Frankfurt and ZEW Mannheim.

Flanagan, Robert (1999). Macroeconomic Performance and Collective Bargaining: An International Perspective. Journal of Economic Literature, XXXVII, 1150-1175.

Goerke, Laszlo, \& Madsen, Jakob (2004). Labour Disputes in the Twentieth Century: an International Comparison and Evaluation of Theories. Homo Oeconomicus, 20(4), 391-421.

Greene, William (2000). Econometric Analysis (5 ed.). New Jersey: Prentice Hall (Pearson Education).

Haffner, Robert, Nickell, Stephen, Nicoletti, Giuseppe, Scarpetta, Stefano, \& Zoega, Gylfi (2001). European Integration, Liberalization, and LaborMarket Performance. In Bertola Giuseppe, Boeri Tito, \& Nicoletti Giuseppe (Eds.), Welfare and Employment in a United Europe (pp. 147-236). MIT Press. 
Hicks, John (1962). The Theory of Wages (2 ed.). New York: MacMillan.

Hoel, Michael, Moene, Karl, \& Wallerstein, Michael (1993). Bargaining Structure and Economic Performance. In Flanagan Robert, Moene Karl, \& Wallerstein Michael (Eds.), Trade Union Behaviour, PayBargaining, and Economic Performance (pp. 6-62). Oxford: Clarendon Press.

Iversen, Torben (1998). Wage Bargaining, Central Bank Independence, and the Real Effects of Money. International Organization, 52(3), 469-504.

Iversen, Torben (1999). Contested economic institutions. Cambridge University Press.

Kennan, John, \& Wilson, Robert (1989). Strategic Bargaining Models and Interpretation of Strike Data. Journal of Applied Econometrics, 4(0), S87-S130.

Kennan, John, \& Wilson, Robert (1990). Can Strategic Bargaining Models Explain Collective Bargaining Data? American Economic Review, 80(2), 405-09.

Kennan, John, \& Wilson, Robert (1993). Bargaining with Private Information. Journal of Economic Literature, 31(1), 45-104.

Kenworthy, Lane (2001). Wage Setting Measures: A Survey and Assessment. World Politics, 54(1), 57-98.

Layard, Richard, Nickell, Stephen, \& Jackman, Richard (1991). Unemployment (first ed.). Oxford: Oxford University Press.

Lesch, Hagen (2002). Streik und Arbeitskampfregeln im internationalen Vergleich. IW-Trends (Institut der Deutschen Wirtschaft Köln), 29(2), 5-17.

Ochel, Wolfgang, \& Selwitschka, Markus (2003). Hoher Arbeitsfriede in Deutschland. Ifo Schnelldienst, 56(8), 44-47.

OECD (1997). Employment Outlook. Paris.

Powell, James (1996). Rescaled Methods-of-Moments Estimation for the Box-Cox Regression Model. Economics Letters, 51, 259-265. 
Schmitter, Philippe (1981). Interest Intermediation and Regime Governability in Contemporary Western Europe and North America. In Berger S. (Ed.), Organizing Interests in Western Europe (pp. 285-330). Cambridge University Presse.

Schnabel, Claus (1993). Korporatismus, zentralisierte Tarifverhandlungen und makroökonomische Performance. Zeitrschrift für Wirtschaftspolitik, 42(3), 259-272.

Schnabel, Claus (1995). Arbeitskämpfe im internationalen Vergleich - Trends und Einflussfaktoren. IW-Trends, 22(1), 43-56.

Tarantelli, Ezio (1986). The Regulation of Inflation and Unemployment. Industrial Relations, 25, 1-15.

Teulings, Coen, \& Hartog, Joop (1998). Corporatism or Competition? Labour Contracts, Institutions and Wage Structures in International Comparison. Cambridge: Cambridge University Press.

Vinod, H. D. (1993). Bootstrap Methods: Applications in Econometrics. In Maddala G. S., Rao C. R., \& Vinod H. D. (Eds.), Handbook of Statistics (Vol. 11, pp. 629-662). Amsterdam: North Holland. 


\section{A Tables}

\section{A.1 Estimates of the Box-Cox transformation param- eter}

Table 4: Estimates of the transformation parameter $\lambda$

\begin{tabular}{crrrr}
\hline \hline \multicolumn{5}{c}{ group-specific fixed effects specification } \\
Indicator & estimator & point est. & $Q_{0.025}$ & $Q_{0.975}$ \\
\hline CO & NLS & 0.11 & 0.6 & 0.20 \\
CO & NLAD & 0.18 & 0.10 & 0.57 \\
CE & NLS & 0.09 & 0.05 & 0.18 \\
CE & NLAD & 0.14 & 0.06 & 0.85 \\
\hline \multicolumn{5}{c}{ country-specific fixed effects specification } \\
NLS & 0.076 & 0.02 & 0.18 \\
$Q_{0.025}, Q_{0.975}:$ & NLAD & 0.19 & 0.05 & 0.44 \\
\multicolumn{7}{c}{ 2. and $97.5 \%$ percentile of bootstrap distribution of $\lambda}$.
\end{tabular}

\section{B Description of the Bootstrap Procedure}

Let $z_{i, t}=\left[x_{i, t}, y_{i, t}\right]$ denote a row of the data matrix including all regressors and the dependent variable. A time block $\xi_{i, t}$ consists of four successive observations, i.e. $\xi_{i, t}=\left(z_{i, t}, \ldots, z_{i, t+3}\right)$, and a panel block $\psi_{t}$ consists of six randomly sampled time-blocks, i.e. $\psi_{t}=\left(\xi_{r_{1}, t}, \ldots, \xi_{r_{6}, t}\right)$ where the pseudo random numbers $r_{j}$ follow a discrete uniform distribution in the interval $\left[1, \ldots, \tilde{N}_{t, t+3}\right]$ where $\tilde{N}_{t, t+3}$ denotes the number of countries with observations in period $[t, t+3]$. In several panel data applications of the moving-blocks bootstrap, cross-section blocks are formed according to spatial neighbourhood. Since the spatial notion of neighbourhood is not applicable consequently in our application (to see this try to find all direct neighbours of Australia) and moreover residual correlations may follow a different structure, we have to take potluck with this simple randomised design. With six out of 17 countries the chance to retain relevant contemporaneous correlations is quite high. 


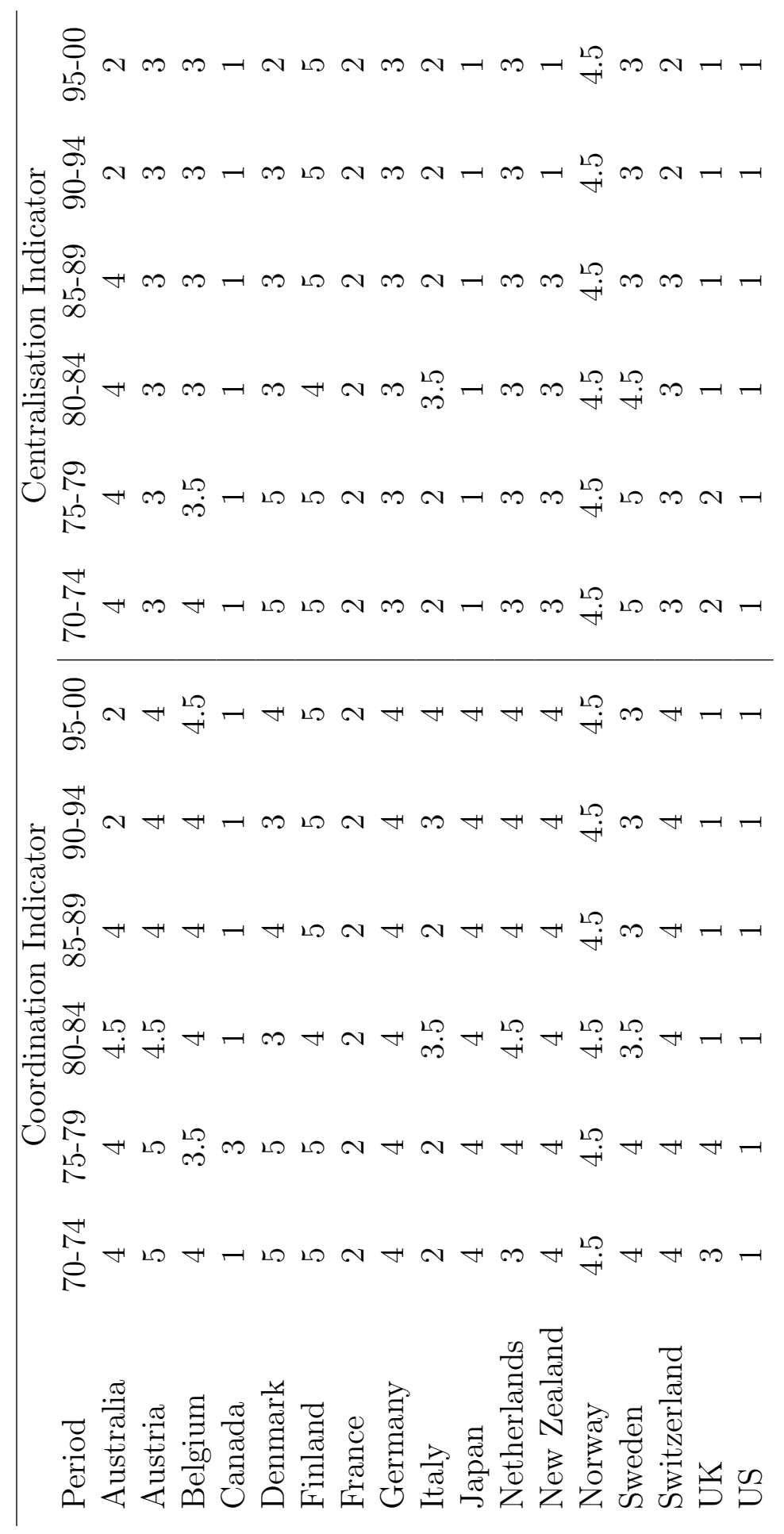

Table 5: OECD indicator of bargaining coordination and centralisation. Source: OECD (2004) 


\section{In dieser Reihe sind zuletzt erschienen Recently published}

\begin{tabular}{|c|c|c|c|}
\hline No. & Author(s) & Title & Date \\
\hline $1 / 2004$ & $\begin{array}{l}\text { Bauer, Th. K., } \\
\text { Bender, St., } \\
\text { Bonin, H. }\end{array}$ & $\begin{array}{l}\text { Dismissal Protection and Worker Flows in } \\
\text { Small Establishments }\end{array}$ & $7 / 2004$ \\
\hline $2 / 2004$ & $\begin{array}{l}\text { Achatz, J., } \\
\text { Gartner, H., } \\
\text { Glück, T. }\end{array}$ & $\begin{array}{l}\text { Bonus oder Bias? Mechanismen geschlechts- } \\
\text { spezifischer Entlohnung }\end{array}$ & $7 / 2004$ \\
\hline $3 / 2004$ & $\begin{array}{l}\text { Andrews, M., } \\
\text { Schank, Th., } \\
\text { Upward, R. }\end{array}$ & $\begin{array}{l}\text { Practical estimation methods for linked } \\
\text { employer-employee data }\end{array}$ & $8 / 2004$ \\
\hline $4 / 2004$ & $\begin{array}{l}\text { Brixy, U., } \\
\text { Kohaut, S., } \\
\text { Schnabel; C. }\end{array}$ & $\begin{array}{l}\text { Do newly founded firms pay lower wages? } \\
\text { First evidence from Germany }\end{array}$ & 9/2004 \\
\hline $5 / 2004$ & $\begin{array}{l}\text { Kölling, A, } \\
\text { Rässler, S. }\end{array}$ & $\begin{array}{l}\text { Editing and multiply imputing German estab- } \\
\text { lishment panel data to estimate stochastic } \\
\text { production frontier models }\end{array}$ & $10 / 2004$ \\
\hline $6 / 2004$ & $\begin{array}{l}\text { Stephan, G, } \\
\text { Gerlach, K. }\end{array}$ & $\begin{array}{l}\text { Collective Contracts, Wages and Wage } \\
\text { Dispersion in a Multi-Level Model }\end{array}$ & $10 / 2004$ \\
\hline 7/2004 & $\begin{array}{l}\text { Gartner, H. } \\
\text { Stephan, G. }\end{array}$ & $\begin{array}{l}\text { How Collective Contracts and Works Councils } \\
\text { Reduce the Gender Wage Gap }\end{array}$ & $12 / 2004$ \\
\hline $1 / 2005$ & $\begin{array}{l}\text { Blien, U., } \\
\text { Suedekum, J. }\end{array}$ & $\begin{array}{l}\text { Local Economic Structure and Industry } \\
\text { Development in Germany, 1993-2001 }\end{array}$ & $1 / 2005$ \\
\hline $2 / 2005$ & $\begin{array}{l}\text { Brixy, U., } \\
\text { Kohaut, S., } \\
\text { Schnabel, C. }\end{array}$ & $\begin{array}{l}\text { How fast do newly founded firms mature? } \\
\text { Empirical analyses on job quality in start-ups }\end{array}$ & $1 / 2005$ \\
\hline 3/2005 & $\begin{array}{l}\text { Lechner, M., } \\
\text { Miquel, R., } \\
\text { Wunsch, C. }\end{array}$ & $\begin{array}{l}\text { Long-Run Effects of Public Sector Sponsored } \\
\text { Training in West Germany }\end{array}$ & $1 / 2005$ \\
\hline $4 / 2005$ & $\begin{array}{l}\text { Hinz, Th., } \\
\text { Gartner, H. }\end{array}$ & $\begin{array}{l}\text { Lohnunterschiede zwischen Frauen und } \\
\text { Männern in Branchen, Berufen und Betrieben }\end{array}$ & $2 / 2005$ \\
\hline $5 / 2005$ & $\begin{array}{l}\text { Gartner, H., } \\
\text { Rässler, S. }\end{array}$ & $\begin{array}{l}\text { Analyzing the Changing Gender Wage Gap } \\
\text { based on Multiply Imputed Right Censored } \\
\text { Wages }\end{array}$ & $3 / 2005$ \\
\hline
\end{tabular}


6/2005 Alda, H., Bender, S., Gartner, $\mathrm{H}$.

7/2005 Haas, A., Rothe, Th.
The linked employer-employee dataset of the IAB (LIAB)

Labour market dynamics from a regional perspective

The multi-account system

8/2005 Caliendo, M., Identifying Effect Heterogeneity to Improve Hujer, R., Thomsen, S.L. Germany

9/2005

Gerlach, K., Stephan, G.

10/2005 Gerlach, K., Individual Tenure and Collective Contracts Stephan, G.

11/2005 Blien, U., Hirschenauer, F.

Formula allocation: The regional allocation of budgetary funds for measures of active labour market policy in Germany

12/2005 Alda, H., Allaart, P., Bellmann, L.

Churning and institutions - Dutch and German establishments compared with micro-level data

$13 / 2005$

Caliendo, M., Hujer, R., Thomsen, St.

Individual Employment Effects of Job Creation Schemes in Germany with Respect to Sectoral Heterogeneity

14/2005 Lechner, M.; The Curse and Blessing of Training the Miquel, R., $\quad$ Unemployed in a Changing Economy Wunsch, C. - The Case of East Germany after Unification

15/2005 Jensen, U.; Where have all the data gone? Stochastic Rässler, S. $\quad$ production frontiers with multiply imputed German establishment data

16/2005 Schnabel, C.; Collective bargaining structure and ist deterZagelmeyer, minants: An empirical analysis with British and S.; Kohaut, S. German establishment data

17/2005 Koch, S:; Workfare: Möglichkeiten und Grenzen Stephan, G.; Walwei, $U$.

18/2005 Alda, $\mathrm{H} . ;$ Wage Structure and Labour Mobility in the Bellmann, L.; $\quad$ West German Private Sector 1993-2000 Gartner, $\mathrm{H}$.

19/2005 Eichhorst, W.; The Interaction of Labor Market Regulation Konle-Seidl, R. and Labor Market Policies in Welfare State Reform $8 / 2005$

$3 / 2005$

$4 / 2005$

$4 / 2005$

$4 / 2005$

$4 / 2005$

$4 / 2005$

$5 / 2005$

$5 / 2005$

$6 / 2005$

$7 / 2005$

$8 / 2005$

$8 / 2005$

9/2005 
20/2005 Gerlach, K.; Tarifverträge und betriebliche Entlohnungs- $\quad$ 11/2005 Stephan, G. strukturen

21/2005 Fitzenberger, Employment Effects of the Provision of $11 / 2005$ B.; Speckes- Specific Professional Skills and Techniques ser, S. in Germany 


\section{Impressum}

IABDiscussionPaper

No. 22 / 2005

\section{Herausgeber}

Institut für Arbeitsmarkt- und Berufsforschung der Bundesagentur für Arbeit

Weddigenstr. 20-22

D-90478 Nürnberg

\section{Redaktion}

Regina Stoll, Jutta Palm-Nowak

Technische Herstellung Jutta Sebald

\section{Rechte}

Nachdruck - auch auszugsweise - nur mit Genehmigung des IAB gestattet

\section{Bezugsmöglichkeit}

Volltext-Download dieses DiscussionPaper

unter:

http://doku.iab.de/discussionpapers/2005/dp2205.pdf

IAB im Internet

http://www.iab.de

Rückfragen zum Inhalt an

Johannes Ludsteck, Tel. 0911/179-4810,

oder e-Mail: johannes.ludsteck@iab.de 